\title{
Designing the blog: A Study with the social science students at Kuala Lumpur Infrastructure University, Malaysia
}

\begin{abstract}
This paper investigates the learning styles amongst the social science students when designing a blog. A blog or a weblog is a website where entries are written in chronological order and commonly displayed in reverse chronological order. A typical blog combines text, images, and links to other blogs, web pages, and other media related to its topic. The subjects in this study consist of 6 students from Kuala Lumpur Infrastructure University, Malaysia (KLIUC). There were three international students from China and three local students from Malaysia. The students were not exposed to designing blog as they were from Bachelor of English for Professional Communication program. One of the courses in the program is the Language and Computer and they were to design their own blog in six weeks. The program that they used was the Microsoft Front Page. It is found that all the subjects have tactile and kinesthetic learning styles. Three subjects preferred to include graphics and music and therefore they preferred the visual and audio learning styles. Reid's (1987) learning style preference was used for the purpose of this study.
\end{abstract}

Keyword: Learning Style Preference, Designing Blog 